\title{
Evaluation of a Prototype for Water Heating in Agroindustries Using Foucault Current
}

\author{
Marcos Vinícius Schlichting ${ }^{1,2}$, Carlos Eduardo Camargo Nogueira ${ }^{1}$, Reinaldo Aparecido Baricatti ${ }^{1}$, \\ Tatiane Martins de Assis ${ }^{1} \&$ Jair Antonio Cruz Siqueira ${ }^{1}$ \\ ${ }^{1}$ State University of Western Paraná, Cascavel Campus, Cascavel, Brazil \\ ${ }^{2}$ Federal Technological University of Paraná, Toledo Campus, Toledo, Brazil \\ Correspondence: Marcos Vinicius Schlichting, Federal Technological University of Paraná, Toledo Campus, \\ Toledo, Brazil. Email: marvim_s@hotmail.com
}

Received: October 17, 2018

Accepted: November 18, 2018

Online Published: January 15, 2019

doi:10.5539/jas.v11n2p217

URL: https://doi.org/10.5539/jas.v11n2p217

\begin{abstract}
Based on the observation of the effects of energy generation on climate change, efforts have been carried out to develop technologies to reduce polluting energy sources. In this context, the rational use and improvement of the efficiency of water heating systems can play an important role, contributing to lower energy consumption. This study evaluated a prototype for water heating for use in agroindustry. The prototype was designed for a possible utilization of mechanical energy in order to change the magnetic flux produced by permanent magnets, generating thermal energy by Foucault currents. This system presented yields of $64.74 \%, 65.13 \%$ and $64.48 \%$ for the rotor configurations with six magnets without pole reversal (6ISI), four magnets with reversal (4ICI), and four magnets without reversal (4ISI), respectively. For comparison purposes, a resistive water heating system was also evaluated for the same study conditions, obtaining an efficiency of $89.21 \%$. The proposed inductive system did not present satisfactory results for constructive conditions presented in the study.
\end{abstract}

Keywords: water heating, magnetic induction, permanent magnets

\section{Introduction}

Water heating in agroindustry, for the most varied purposes, often comes from the burning of wood, due to its good cost-benefit ratio. Electricity for heating water has higher costs and is usually performed by resistive electrical systems. Coupled with this, the overall increase in energy consumption between 2011 and 2035 will be around 33\% (International Energy Agency, 2013). In Brazil, the year 2017 witnessed an increase in energy consumption by 1.8\% compared to 2016 (Ministry of Mines and Energy, 2018); a minimum growth rate in end energy consumption of $2.2 \%$ per year is projected for $2010-2030,39 \%$ of the total consumption is represented by industries (Ministry of Mines and Energy, 2016). Thus, the development and/or application of technologies to reduce water and energy consumption are key factors to improve competitiveness in agroindustries (Taibi, Gielen, \& Bazilian, 2012; Carrasquer, Uche, \& Martínez-Gracia, 2017).

There is an abundant consumption of heated or steamed water in the various production and manufacturing processes, such as in the beverage, food and dairy industries. This water is used for drying, dehydration processes, pasteurization processes, chemical reactions, cleaning, and heating of agroindustrial environments with temperatures of up to $260{ }^{\circ} \mathrm{C}$ (Kalogirou, 2003; Mekhilief, Saidur, \& Safari 2011; Carreira Junior, Sacomano, \& Mollo Neto, 2014; Jordan, Cortez, Barbin, \& Lucas, 2016).

In Brazil, it is estimated that energy efficiency strategies may account for up to $18 \%$ of total energy consumption and $17 \%$ of electricity by 2050 . Examples of these strategies are the use of biogas for heating or distributed generation, solar energy, and processes optimization, among others (Ministry of Mines and Energy, 2016). In particular in the dairy industry, in which up to $20 \%$ of the electricity consumption is for water heating, Baldassin et al. (2004) proposed a heat recovery system for preheating water, using the heating of the heat pumps of the milk cooling system.

Magnetic induction heating, through high-frequency inductors, is widely used in the metalworking industry for metal melting, heat treatment, localized heating, and fluid heating. Heating occurs in the presence of parasitic currents (Foucault currents), by exposing the conductive material to alternating magnetization cycles, which in 
turn dissipate thermal energy (Joule effect). Heating intensity is a function of the frequency of the cycle of magnetization (Castro, Rodrigues, Landgraf, \& Yonamine, 2002). Induction techniques can be used to heat metal surfaces at frequencies in the range of $50 \mathrm{~Hz}$ to $1 \mathrm{MHz}$ (Jones, Taylor, Nakai, \& Jennings, 2003).

The development of inductive heating enables the application of this technology beyond the industry for domestic, medicinal and other uses. The process uses induction coils to perform the heating and offers numerous advantages such as high efficiency, heating without direct contact, accurate temperature control, and the non-use of heating through fossil fuels (Lucía, Maussion, Dede, \& Burdío, 2014).

Romanovsky and Mutale (2012) evaluated low-frequency magnetic induction for water heating, inducing Foucault currents on the walls of the tank. The tank was made of a ferromagnetic material, which acts as an inductor core and thermal energy heatsink. The system was considered technically feasible for the procedure.

When analyzing models of inductive heaters for residential environments, Popa and Pentuic (2012) concluded that, in addition to the efficiency of approximately $90 \%$, inductive devices are safer, have lower maintenance costs, and may represent a solution for the utilization of thermal energy losses in various devices.

One way to obtain a variable magnetic field is by moving permanent magnets. Movement from a water wheel, a combustion engine or any other source of mechanical energy can produce parasitic currents in paramagnetic or diamagnetic materials generating heat that can be used for heating water.

Based on the above, this study aimed to build and evaluate a water heating prototype using Foucault currents, generated by the variation of the magnetic field provided by permanent magnets.

\section{Material and Methods}

The work was carried out at the Energy Laboratory (LENE) of the State University of Western Paraná (UNIOESTE), Cascavel Campus, Paraná, Brazil. The study consisted of the building and evaluation of a prototype for direct water heating by magnetic induction, Figure 1B.

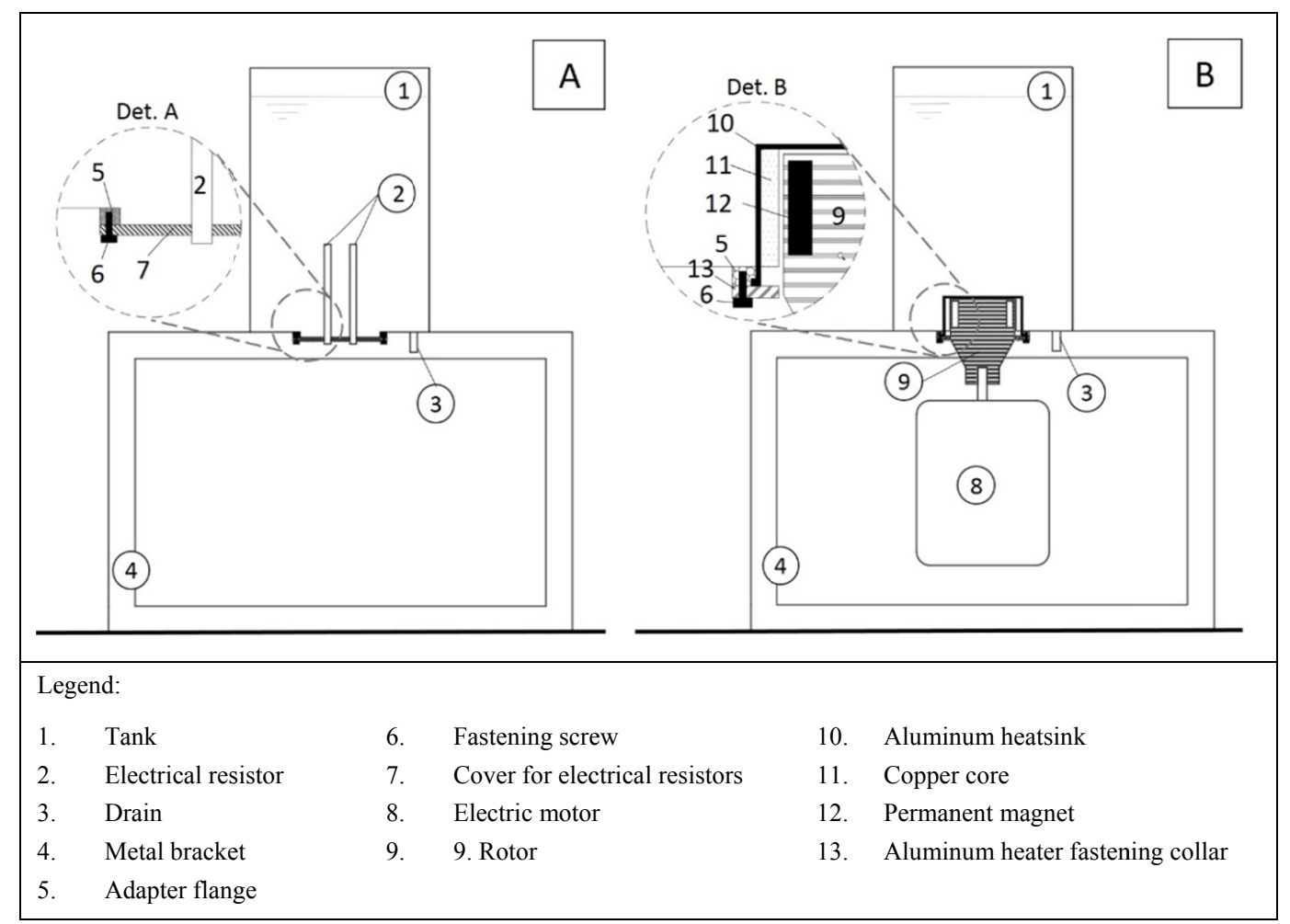

Figure 1. Layout of the water heating prototype. (A) Resistive system. (B) Inductive system

The Foucault currents came from the variation of the magnetic flux caused by permanent magnets, using the mechanical energy supplied by an electric motor.

The prototype had a cylindrical aluminum tank (capacity for 20 liters), insulated thermally with aluminum blanket and polyurethane foam. The following parameters were monitored: 
- Volume of water: measured by weight, with $15 \mathrm{kgf}$, on a precision scale in order to enable calculation of the amount of heat and energy;

- Initial system temperature: the initial temperature of the water mass was approximately $25^{\circ} \mathrm{C}$, measured using a mercury thermometer, with a graduation from $0{ }^{\circ} \mathrm{C}$ to $100{ }^{\circ} \mathrm{C}$;

- Maximum stipulated temperature for the system water: $80{ }^{\circ} \mathrm{C}$, temperature commonly used in agroindustrial processes, dairy products, sterilization, cleaning (Kalogirou, 2003; Mekhilief et al., 2011; Carvalho et al., 2014; Jordan et al., 2016). For the measurement and collection of water temperature data of the system, a digital multimeter of the Icel brand, MD-6450 model, equipped with a K-type thermocouple temperature sensor, for up to $250{ }^{\circ} \mathrm{C}$, was used. The thermocouple was positioned in the center and middle portion of the tank.

In the lower part of the tank, a flange was placed to enable the exchange of heating systems using the same tank: conventional resistive system (Scenario 1) and proposed inductive systems (Scenarios 2 and 3). For each scenario, three repeats of heating water temperature measurements were performed.

\subsection{Conventional Resistive Heating}

The conventional resistive system (RES), called "Scenario 1", was implemented for comparison with the proposed inductive systems. In this system, two tubular electrical resistors were installed, with a total power of $600 \mathrm{~W}$. The resistors were coupled in a polyacetal cover, attached to the bottom of the reservoir, according to Figure 1A.

\subsection{Inductive Heating}

The inductive system, shown in Figure 1B, is composed of: (i) aluminum cylinder with copper core, attached to the flange at the bottom tank; (ii) permanent magnet rotor, machined from polyacetal. The rotor is designed for 4 and 6 magnets of $10 \times 20 \times 40 \mathrm{~mm}$. Neodymium, iron and boron magnets, grade N-35 (KOIMAS, 2018), were used; (iii) three-phase 2-pole electric motor, $220 \mathrm{~V}$ voltage, $1 \mathrm{hp}$ power, $3415 \mathrm{rpm}$ rotation, connected to the electrical grid in a triangle configuration. The motor was used to simulate a source of mechanical energy and to move the permanent magnet rotor, creating the variation of the magnetic flux.

The current and voltage data in the test with the resistive heating system were measured using a digital ammeter of the Minipa brand, ET4090 model. For the measurement of the energy consumption of the electric motor, an energy analyzer of the Instrutherm brand, AE200 model was used.

Heat sampling of the water mass, a data series was shown within 5 minutes to the maximum stipulated temperature of $80^{\circ} \mathrm{C}$.

The evaluation of the heating system occurred in order to verify how much thermal energy was made available to the water mass by the induced currents in the heatsink. Different configurations of the permanent magnet rotor were made by modifying the quantities of magnets in order to analyze the influence of the frequency of relative variation of the magnetic flux. To verify the dipolar interaction in the heatsink material, the condition of reversal and non-reversal of the poles of the permanent magnets was established.

In order to establish a common parameter of correlation between the different configurations in the inductive system by permanent magnets, it was necessary to calculate the frequency of variation of the magnetic flux in relation to the heatsink, using Equation 1.

$$
f=p \cdot(n s / 120)
$$

Where,

$f$ is the frequency of the magnetic flux $(\mathrm{Hz}) ; p$, the number of poles of the motor; $n s$, the synchronous rotation of the engine (rpm).

Thus, the inductive system was divided into two evaluation scenarios, which are:

- Scenario 2-rotor composed of six permanent magnets: relative frequency of the magnetic field variation of approximately $170 \mathrm{~Hz}$.

- $\quad$ System with pole reversal (6ICI), Figure 2A;

- $\quad$ System without pole reversal (6ISI), Figure 2B.

- Scenario 3-rotor composed of four permanent magnets: relative frequency of the magnetic field variation of approximately $113 \mathrm{~Hz}$.

- $\quad$ System with pole reversal (4ICI), Figure 2C; 
- $\quad$ System without pole reversal (4ISI), Figure 2D.

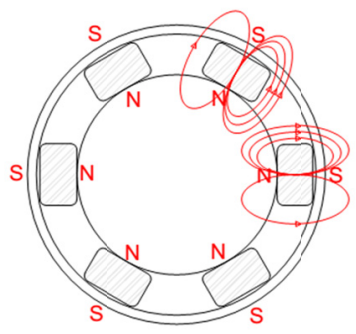

(A)

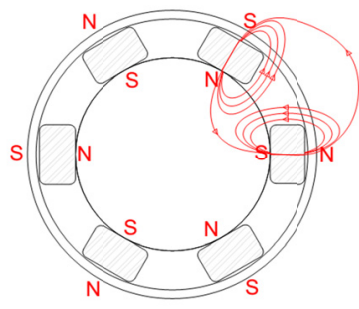

(B)

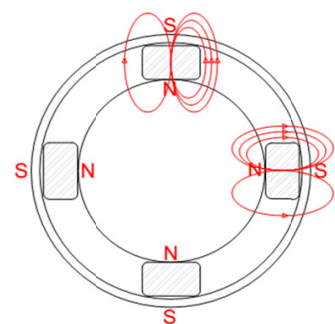

(C)

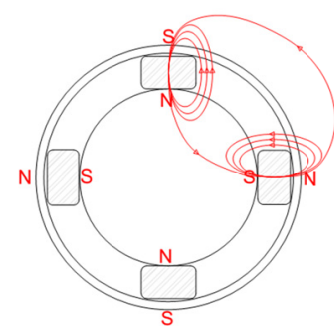

(D)

Figure 2. Magnet layout and polarization. (A) Rotor with six magnets without polarity reversal; (B) Rotor with six magnets with polarity reversal; (C) Rotor with four magnets without polarity reversal. (D) Rotor with four magnets with polarity reversal

\subsection{Heating Efficiency Calculations}

The thermal energy used for heating the water mass (ETAA) was calculated by the fundamental calorimetry Equation 2.

$$
E T A A=1.163 \times 10^{-6} \cdot m \cdot c \cdot \Delta T
$$

Where,

ETAA is the thermal energy for heating water $(\mathrm{kWh}) ; \mathrm{m}$, the mass of water $(\mathrm{kg})$; $\mathrm{c}$, the specific heat of the water $\left(\mathrm{cal} / \mathrm{g}^{\circ} \mathrm{C}\right) ; \Delta \mathrm{T}$, the temperature variation $\left({ }^{\circ} \mathrm{C}\right)$.

The electricity consumed by the grid (EECR) was obtained by Equation 3.

$$
E E C R=P \cdot \Delta t
$$

Where,

EECR is the electricity used $(\mathrm{kWh}) ; \mathrm{P}$, the power consumed $(\mathrm{kW}) ; \Delta \mathrm{t}$, the heating time (hours).

For the calculation of the heating efficiency (n), the quotient between ETAA and EECR was considered, as shown in Equation 4.

$$
n=(E T A A / E E C R) \times 100
$$

\section{Results and Discussion}

\subsection{Scenario 1 Results}

The results obtained from the resistive system design are presented in Table 1.

The overall mean represents the average of the three replicates evaluated in this study, analyzing the energies

\begin{tabular}{|c|c|c|c|c|c|c|}
\hline Repeat & 1 & & 2 & & 3 & \\
\hline Energy (kWh) & EECR & ETAA & EECR & ETAA & EECR & ETAA \\
\hline Sum & 1.057 & 0.925 & 1.085 & 0.977 & 1.084 & 0.977 \\
\hline Yield (\%) & \multicolumn{2}{|l|}{87.46} & \multicolumn{2}{|l|}{90.03} & \multicolumn{2}{|l|}{90.15} \\
\hline \multirow[t]{2}{*}{ Overall Mean } & \multicolumn{2}{|l|}{ EECR } & \multicolumn{2}{|l|}{ ETAA } & \multicolumn{2}{|c|}{ Yield (\%) } \\
\hline & \multicolumn{2}{|l|}{1.075} & \multicolumn{2}{|l|}{0.959} & \multicolumn{2}{|l|}{89.21} \\
\hline
\end{tabular}
involved it can be inferred that the average yield of the system was $89.21 \%$.

Table 1. Resistive system data

Note. EECR = electricity used; ETAA = thermal energy for heating water.

The mean of the data obtained in the test is shown in Figure 3. 


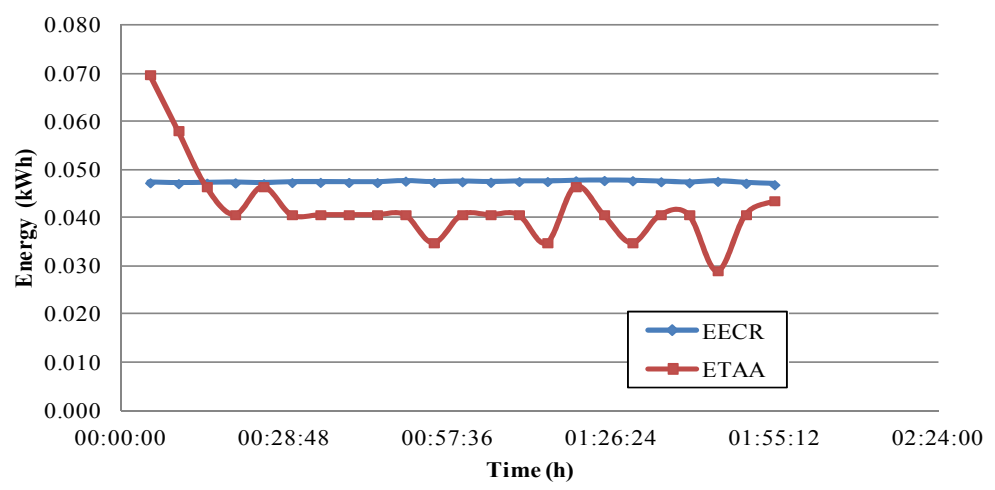

Figure 3. EECR/ETAA comparison between for the resistive system

When verifying the information shown in Figure 3, it is verified that the ETAA presents in greater availability at the beginning of the cycle and that tends to dissipate over time, as convergence shows. The observed oscillation can be explained by the proximity of the temperature sensor of the heat source and the frequency in the acquisition of the data, since the thermal exchanges generate convection currents inside the reservoir.

\subsection{Scenario 2 Results}

Table 2 presents the results for the 6ISI condition (six magnets without pole reversal).

A slight reduction in yield is observed over the repeats of the test, from $65.15 \%$ to $64.07 \%$. This fact can be attributed to the heating of the magnets, as explained by Lenz's law (Young, 2004). The induced currents in the heatsink generate a magnetic field capable of producing induced currents in the magnets, thereby heating them. Permanent magnets exposed to heat suffer a gradual loss of magnetic field intensity up to Curie temperature, where the total field loss occurs. In composite magnets of $\mathrm{NdFeB}$, as used in this study, the Curie point is close to $300^{\circ} \mathrm{C}$ (Cullity \& Gaham, 2009).

Table 2. 6ISI inductive system data

\begin{tabular}{lllllll}
\hline Repeat & 1 & & 2 & & 3 & \\
\hline Energy $(\mathrm{kWh})$ & EECR & ETAA & EECR & ETAA & EECR & ETAA \\
Sum & 1.499 & 0.977 & 1.476 & 0.959 & 1.470 & 0.942 \\
Yield $(n)$ & 65.15 & & 65.02 & & 64.07 & \\
Overall Mean & EECR & ETAA & Yield & \\
& 1.482 & 0.959 & 64.75 & \\
\hline
\end{tabular}

Note. EECR = electricity used; ETAA = thermal energy for heating water.

The mean of the data obtained in the test is shown in Figure 4.

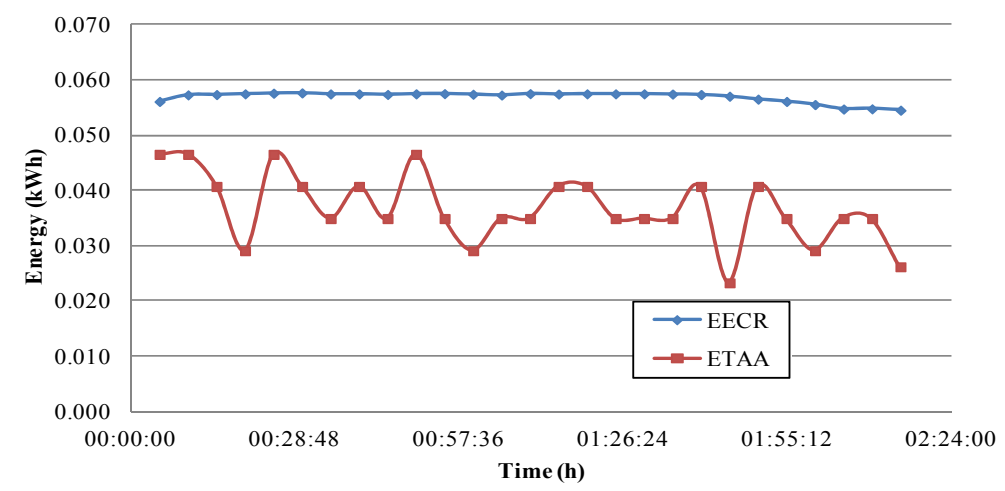

Figure 4. EECR/ETAA comparison for the 6ISI configuration 
In the analysis of Figure 4, which illustrates the average yield between the repeats of the test, it is found that the lines representing EECR and ETAA indicate an energy reduction in the process. This corroborates with the theory of the loss of magnetic intensity and subsequent reduction of the force against electromotive force caused by the heating of the magnets (Cullity \& Gaham, 2009).

In the 6ICI configuration (Figure 2B), six magnets with pole reversal, the magnetic field generated an electromotive force with high magnitude. An increase in the electric current with possible overload in the motor was observed, and the test for this configuration was discontinued.

\subsection{Scenario 3 Results}

The results of the first condition of scenario 3, four magnets with pole reversal (4ICI), are presented in Table 3 . With the reduction of the number of magnets, the relative frequency of the magnetic flux variation was reduced by $170 \mathrm{~Hz}$ (frequency practiced in the Scenario 1), reaching $113 \mathrm{~Hz}$, which represents a 33\% reduction. In this context, a reduction in the induced currents is suggested, as the Foucault currents are directly proportional to the magnetic flux variation (Castro et al., 2002). Nevertheless, the average yield was $65.13 \%$, slightly higher than that of the 6ISI system, which was $64.75 \%$. The increase in yield suggests a better heatsink response to the dipolar interaction by the reversal of the magnet poles. The reversal of the magnet poles offers complete cycles of magnetic hysteresis, thereby increasing the energy involved in the process (Cullity \& Gaham, 2009).

Table 3. 4ICI inductive system data

\begin{tabular}{lllllll}
\hline Repeat & 1 & & 2 & & 3 & \\
\hline Energy $(\mathrm{kWh})$ & EECR & ETAA & EECR & ETAA & EECR & ETAA \\
Sum & 1.393 & 0.925 & 1.517 & 0.977 & 1.512 & 0.977 \\
Yield $(n)$ & 66.39 & & 64.42 & & 64.59 & \\
Overall Mean & EECR & ETAA & Yield & \\
& 1.474 & 0.959 & 65.13 & \\
\hline
\end{tabular}

Note. $\mathrm{EECR}=$ electricity used; ETAA = thermal energy for heating water.

The mean of the data obtained in the test is shown in Figure 5.

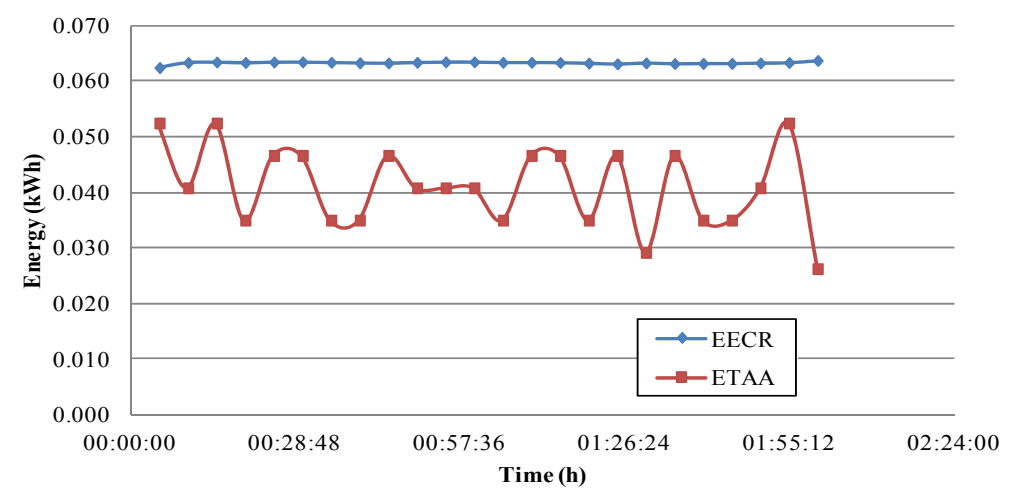

Figure 5. EECR/ETAA comparison for the 4ICI configuration

A constant behavior of the EECR is observed in Figure 5, which suggests a lower degree of heating of the magnets. With the lower heating of the magnets, maintenance of the magnetic field occurs, as well as the generation of counter-electromotive force, providing constant thermal energy. The ETAA is also more constant over time, which may respond to the better observed yield, suggesting that there was a lower working temperature of the magnets and better yield compared to the first condition of Scenario 2 (6ISI).

Scenario 3 presents the condition of non-reversal of the polarity of the magnets (4ISI), whose results are presented in Table 4.

In this condition, it is observed that there was decrease in system yield, when compared with the two previous conditions. This can be explained by both frequency reduction and dipole interaction. The polarization of the 
magnets showed an effect on the dissipated energy, as the analysis of the two conditions of Scenario 3 (4ICI and 4ISI) show that the best yield was obtained when the pole reversal occurred.

Table 4. 4ISI inductive system data

\begin{tabular}{lllllll}
\hline Repeat & 1 & & 2 & & 3 & \\
\hline Energy $(\mathrm{kWh})$ & EECR & ETAA & EECR & ETAA & EECR & ETAA \\
Sum & 1.517 & 0.959 & 1.516 & 0.994 & 1.513 & 0.977 \\
Yield $(n)$ & 63.24 & & 65.59 & & 64.59 & \\
Overall Mean & EECR & ETAA & Yield & \\
& 1.515 & & 0.977 & 64.48 & \\
\hline
\end{tabular}

Note. EECR = electricity used; ETAA = thermal energy for heating water.

The mean of the data obtained in the test is shown in Figure 6.

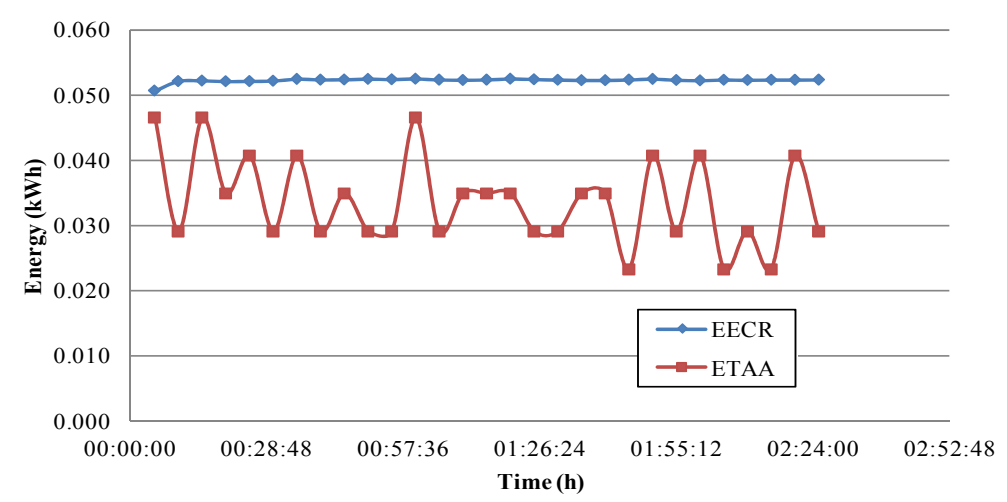

Figure 6. EECR/ETAA comparison for the 4ISI configuration

In the tests performed in Scenario 3, it is verified that the behavior of the data in the graphs was quite similar, differing only in the magnitude of the values presented (Figure 6).

In the analysis of the polarity reversal, it was verified that the instantaneous electricity consumed of the network, observed in each reading interval, was $16.4 \%$ smaller for 4ISI configuration in relation to 4ICI. For the instantaneous thermal energy used for water heating, the reduction was $15.4 \%$.

In general, the yield values presented in the evaluations of the inductive systems with permanent magnets, regardless of the number and polarity configuration of the magnets, were around $65 \%$. These yield values were also verified in solar systems for preheating water in agroindustrial boilers (Celuppi, Scapinello, Adrade, Revello, and Dal Magro, 2014).

Comparing the three configurations of the inductive system, it can be observed that, even when operating at a relative frequency around 33\% lower, the four-magnet system with reversal (4ICI) presented better efficiency than the six-magnet system without inversion (6ISI). This is possibly due to polarity reversal, which can be attested by the fact that the pole reversal in the six-magnet configuration eventually overloaded the system motor.

\section{Conclusion}

When evaluating the prototype, it was observed that it is possible to use a permanent magnet to generate thermal energy for water heating with an efficiency of $65.13 \%$ (4ICI), $64.48 \%$ (4ISI) and $64.75 \%$ (6ISI). The inductive system idealized for the prototype presented a lower efficiency when compared to the resistive system that was of $89.21 \%$, being not technically feasible within the evaluated constructive conditions.

\section{References}

Baldassin, R. J., Cortez, L. A. B., Jordan, R. A., Neves, L. C. F., Lucas, J. J., \& Pacco, H. C. (2004). Consumo de energia elétrica de um laticínio tipo "A" e estudo de racionalização do uso de energia elétrica nos processos de resfriamento de leite e aquecimento de água: Um estudo de caso. Procedings of the 5th Encontro de 
Energia no Meio Rural, 2004, Campinas (SP). Retrieved from http://www.proceedings.scielo.br/scielo. php?script=sci_arttext\&pid=MSC0000000022004000100041\&lng=en\&nrm=iso

Carrasquer, B., Uche, J., \& Martinez-Gracia, A. (2017). A new indicator to estimate the efficiency of water and energy use inagro-industries. Journal of Cleaner Production, 143, 462-473. https://doi.org/10.1016/j.jclepro. 2016.12.088

Carreira, E. F. J., Sacomano, J. B., \& Mollo, M. (2014). Energia solar térmica: Inovação em aquecimento de água para processos industriais. Brazilian Journal of Biosystems Engineering, 8(3), 209-219.

Castro, N. A., Rodrigues, D., Landgraf, F. J. G., Yonamine, T., \& Henrique, M. L. (2002). Pó de ferro microencapsulado: Efeito do tratamento térmico de recozimento na redução das perdas magnéticas. Anais do Congresso Anual da Associação Brasileira de Metalurgia e Materiais, 891-903.

Celuppi, R., Scapinello, J., Andrade, G. D. F., Revello, H. P. J., \& Dal Magro, J. (2014). Solar energy use for water pre-heating in boilers of agro-industries. Engenharia Agricola, 34(3). https://doi.org/10.1590/S010069162014000300009

Cullity, B. D., \& Graham, C. D. (2009). Introduction to Magnetic Materials (2nd ed.). Hoboken, New Jersey: A John Wiley \& Sons, Inc.

International Energy Agency. (2013). Key World Energy Statistics. Retrieved from http://www.iea.org/ publications/freepublications/publication/KeyWorld2013.pdf

Jones, P. L., Taylor, S., Nakai, S., \& Jennings, J. (2003). Electroheat and Materials Processing (16th ed.). Helitavia. https://doi.org/10.1016/B978-075064637-6/50009-5

Jordan, R. A., Cortez, L. A. B., Barbin, D. F., \& Lucas, J. J. (2016). Bomba de calor para geração de energia térmica em granjas leiteiras. Engenharia Agrícola-Energia na Agricultura, 36(5).

Kalogirou, S. (2003). The potential of solar industrial process heat applications. Applied Energy, 76(4), $337-361$.

KOIMAS. (2018). Retrieved from http://www.koimas.com.br/produtos/neodimio

Lucía, O., Maussion, P., Dede, E. J., \& Burdío, J. M. (2014). Induction heating technology and its applications: Past developments, current technology, and future challenges. Transactions on Industrial Electronics, 61(5). https://doi.org/10.1109/TIE.2013.2281162

Mekhilief, S., Saidur, R., \& Safari, A. (2011). A review on solar energy use in industries. Renewable and Sustainable Energy Reviews, 15(4), 1777-1790. https://doi.org/10.1016/j.rser.2010.12.018

MME (Ministério de Minas e Energia). (2007). Plano Nacional de energia 2030. Retrieved from http://www.abesco.com.br/wp-content/uploads/2015/07/Plano-Nacional-Energia-2030.pdf

MME (Ministério de Minas e Energia). (2016). Demanda energética 2050, nota técnica DEA 13/15. Retrieved from http://www.epe.gov.br/sites-pt/publicacoes-dados-abertos/publicacoes/PublicacoesArquivos/publicaca o-227/topico-202/DEA\%2013-15\%20Demanda\%20de\%20Energia\%202050.pdf

MME (Ministério de Minas e Energia). (2018). Resenha energética brasileira, Exercício 2017. Retrieved from http://www.eletronuclear.gov.br/LinkClick.aspx?fileticket=HMycQw8fVis\%3d\&tabid=69

Romanovsky, G., \& Mutale, J. (2012). Implementation of heat production and storage technology and devices in power systems. Applied Thermal Engineering, 48, 296-300. https://doi.org/10.1016/j.applthermaleng.2012. 05.008

Popa, C., \& Pentuic, R. (2012). Analysis of a new induction thermal converter for heating. Energy, 42, 81-93. https://doi.org/10.1016/j.energy.2011.07.046

Taibi, E., Gielenb, D., \& Bazilian, M. (2012). The potential for renewable energy in industrial applications. Renewable and Sustainable Energy Reviews, 16(1), 735-744. https://doi.org/10.1016/j.rser.2011.08.039

Young, H. D. (2004). Sears \& Zemansky, Física III: Eletromagnetismo (10th ed.). São Paulo: Addison Wesley.

\section{Copyrights}

Copyright for this article is retained by the author(s), with first publication rights granted to the journal.

This is an open-access article distributed under the terms and conditions of the Creative Commons Attribution license (http://creativecommons.org/licenses/by/4.0/). 